\title{
Educación ambiental para el mantenimiento de cuerpos de agua contaminados mediante la IEP
}

\section{Environmental education for the maintenance of contaminated water bodies through the IEP}

DOI: http://dx.doi.org/10.17981/cultedusoc.9.3.2018.40

Artículo de investigación. Fecha de recepción: 15/06/2018. Fecha de aceptación: 27/11/2018

\author{
Ana Cabana-Manjarrez; Mónica Acuña-Rodríguez; Dalia Palacio-Guerra; \\ Dannys Rodríguez-Luran; Dayana Núñez-Palomino; Fanny Pertuz-Angulo; \\ Justina Castillo-Pérez; Ledys Julio-Arrieta; Leonor Quezedo-Rivera; \\ María Castillo-Podlesky; Nazly Zambrano-Barrios; \\ Osman De La Cruz-Jiménez; Sandra Liñán-González; \\ Silvana Rojano-Pabón; Sindy Bolaño-Díaz y Yaneth Mora-Suarez ${ }^{1}$ \\ IED Elvia Vizcaíno de Todaro, sede principal (Colombia)
}

Para citar este artículo:

Cabana-Manjarrez, A., Acuña-Rodríguez, M., Palacio-Guerra, D., Rodríguez-Luran, D., Núñez-Palomino, D., Pertuz-Angulo, F., CastilloPérez, J., Julio-Arrieta, L., Quezedo-Rivera, L., Castillo-Podlesky. M., Zambrano-Barrios, N., De La Cruz-Jiménez, O., Liñán-González, S., Rojano-Pabón, S., Bolaño-Díaz, S. y Mora-Suarez, Y. (2018). Educación ambiental para el mantenimiento de cuerpos de agua contaminados mediante la IEP. Cultura. Educación y Sociedad 9(3), 351-362. DOI: http://dx.doi.org/10.17981/cultedusoc.9.3.2018.40

\section{Resumen}

La educación ambiental es un elemento utilizado desde las escuelas para crear consciencia en la comunidad educativa sobre las problemáticas de contaminación observadas en el contexto social donde habitan, el estudio tuvo como objetivo implementar la educación ambiental para el mantenimiento de cuerpos de agua contaminados mediante la investigación como estrategia pedagógica (IEP). La metodología se orientó bajo el enfoque cualitativo, utilizando el tipo de investigación acción, desde un diseño descriptivo, exploratorio. Para la recolección de datos se utilizaron técnicas como; observación participante y diario de campo. La población estuvo conformada por cincuenta (50) sujetos, para esto se realizó un muestreo no probabilístico de tipo intencional. Los resultados mostraron altos niveles de contaminación en el canal Tolima, por desecho de residuos sólidos, basuras, vertimiento de aguas residuales y uso de jabón y detergentes para lavar la ropa en el Rio, donde los estudiantes con la asesoría y acompañamiento de los maestros diseñaron estrategias educativas basadas en investigación para el mantenimiento de los cuerpos de agua contaminados del canal Tolima en Aracataca, apuntado a la formación de estudiantes con conciencia ciudadana, que aporten a la preservación del medio.

Palabras clave: educación ambiental, cuerpos de agua, contaminación, investigación como estrategia pedagógica.

\section{Abstract}

Environmental education is an element used by schools to create awareness in the educational community about the pollution problems observed in the social context where they live, the study aimed to implement environmental education for the maintenance of contaminated water bodies through research as a pedagogical strategy (IEP). The methodology was oriented under the qualitative approach, using the type of action research, from a descriptive, exploratory design. For the collection of data, techniques such as; participant observation and daily of field. The population consisted of fifty (50) subjects, for this a non-probabilistic sampling of intentional type was carried out. The results showed high levels of contamination in the Tolima channel, by waste of solid waste, garbage, dumping of wastewater and use of soap and detergents to wash clothes in the Rio, where the students with the advice and accompaniment of the teachers designed educational strategies based on research for the maintenance of contaminated water bodies of the Tolima channel in Aracataca, aimed at training students with citizen awareness, which contribute to the preservation of the environment.

Keywords: environmental education, bodies of water, pollution, research as a pedagogical strategy.

1 Maestros de la IED Elvia Vizcaíno de Todaro, sede principal, pertenecientes al grupo de investigación GIPA.

- The author; licensee Universidad de la Costa - CUC.

Cultura, Educación y Sociedad vol. 9 no. 3, pp. 351-362. Diciembre, 2018

Barranquilla. ISSN 2389-7724 Online 


\section{Introducción}

La sociedad actual demanda que las organizaciones reconozcan los impactos que producen sobre el medio en el cual actúan, por tanto, deben ser totalmente responsables en la gestión de su actividad empresarial (Hernández \& Jiménez, 2015). Las escuelas no escapan a esta realidad y ya que la educación es un proceso constructivo, formador de humanos íntegros, con conocimientos y actitudes tendientes a contribuir de manera activa con el desarrollo humano sostenible. Por su parte la educación ambiental no es una asignatura de estudio, como la biología, química o física; es un proceso dinámico y participativo que pretende desarrollar conciencia, actitudes, opiniones y creencias para la adopción de conductas sostenibles en la población educativa, para identificarse y comprometerse con la problemática ambiental local, regional y global. Esta educación busca promover una relación armónica entre las actividades del ser humano y su entorno. Por tal razón el estudio tuvo como objetivo implementar la educación ambiental para el mantenimiento de cuerpos de agua contaminados mediante la investigación como estrategia pedagógica (IEP).

La educación ambiental es un elemento utilizado desde las escuelas para crear consciencia en la comunidad educativa, está debe integrar conocimientos, actitudes y acciones, donde no sólo se informe sobre un determinado problema sino además encontrar respuesta o soluciones para detener y evitar el deterioro ambiental; aún más, se trata de asumir, comprender el problema y actuar sobre él. Es decir, la educación ambiental busca una conducta responsable, conocimientos sobre el medio ambiente y su problemática, además de estrategias para actuar sobre y para el medio (Navarro y Garrido, 2006), donde todas las personas que intervienen en la planificación estratégica de su acción misma, esperan mejorar las instituciones, "para hacerlas más eficientes, más humanas, más racionales, más útiles y rentables para las sociedades" (Mendoza, López, \& Salas, 2016, p. 65), lo anterior desde el sentido dinámico del concepto de medio ambiente, esto es, todo el conjunto de actividades humanas tendientes a evitar la afectación, alteración o puesta en riesgo la existencia de la vida misma (Pereira, 2016).

Por su parte la contaminación es una problemática que a diario transforma el medio que nos rodea, el suelo, aire y agua, afectando la calidad de vida de las personas (Morgado et al., 2018). Siendo el agua fuente de vida para toda la comunidad, su uso inadecuado la está contaminando por la disposición de los recursos sólidos $\mathrm{y}$ otras actividades domésticas que han ocasionado alteraciones en la composición de los ecosistemas acuáticos y la salud humana. En efecto la contaminación hídrica se lleva a cabo por vertidos, derrames, desechos, depósitos directos o indirectos de toda clase de materiales y generalmente, todo hecho susceptible de provocar un incremento de la degradación de las aguas, modificando sus características físicas, químicas o bacteriológicas (Segura, 2007).

El municipio de Aracataca presenta una problemática de contaminación en los cuerpos de agua que abastecen a toda la comunidad, estos son generados principalmente en fuentes y puntos del canal Tolima, el cual abarca la parte central del municipio, encontrándose contaminado debido a la acumulación de desechos sólidos que obstaculizan el flujo de agua, a su vez el mal manejo de aguas residuales, domesticas e industriales, han alterado la calidad de este recurso hídrico, generando problemas sanitarios que ponen en riesgo la vida de los diferentes seres vivos inclusive la de los seres humanos que dependen de este. 
El municipio de Aracataca está ubicado dentro de la segunda vertiente hidrográfica del Departamento del Magdalena. Esta vertiente está dominada por la Ciénaga Grande de Santa Marta, hacia donde vierten sus aguas una gran cantidad de ríos, caños arroyos y quebradas. Dentro del Municipio se encuentra el río Aracataca, que está formado por el río Mamancanaca que a su vez recibe las aguas del Duraimena; el río Piedras que nace en la Sierra Nevada y desemboca en el río Fundación y otros ríos de menor importancia. El casco urbano está regado por el río Aracataca y los canales de riego Antioquia y Tolima que atraviesan el poblado, además recibe aguas del río Fundación, el río Tucurinca y otros ríos menores como el Maranchucua y el Duboncina (Alcaldía de Aracataca, 2017)

Por su parte el Canal Tolima o la acequia fue el gran proveedor de agua para la población en general que carecía entonces de acueducto y tenía una extensión de 12 Kilómetros, desde la bocatoma hasta su desembocadura en el Rio Aracataca. Desde el lugar de su nacimiento el Canal o acequia, recibe el nombre de Canal Antioquia hasta el sitio denominado la Quesera (Sitio que se ha convertido en un balneario muy atractivo para compartir en familia), donde se divide y a partir de ahí recibe el nombre de Canal Tolima y la otra bifurcación Canal Bremen, el cual cruza los barrios Galán, Marujita y las Delicias, ubicados en la parte alta de la población. El Canal Tolima hace parte de la historia del municipio, sin embargo, actualmente se encuentra que para muchos de los habitantes se ha convertido en el depósito de residuos sólidos y materias fecales, contaminando este recurso (Alcaldía de Aracataca, 2017)

El Canal Tolima es un cuerpo de agua superficial que se desprende del Rio Aracataca, este Canal abarca la parte central del municipio y es utilizado por sus habi- tantes para bañarse y recrearse, sin embargo, se observa que también es utilizado para otras actividades como; lavar la ropa con detergentes, lavar motos, verduras y utensilios de los vendedores del mercado, a su vez, otras personas acumulan sus basuras en las esquinas del canal y conectan sus desagües al mismo, observando en dichas actividades fuentes contaminantes que alteran el $\mathrm{PH}$ del agua dejándola no apta para el consumo humano, poniendo en peligro la vida de plantas y animales que habitan en ese ecosistema.

Existen algunos antecedentes a esta investigación, a nivel internacional en México se realizó un estudio titulado: Educación ambiental escolar y comunitaria en el nivel medio superior, el cual muestra que, a través de programas ambientales, conformados por un conjunto de acciones concretas, diseñadas y ejecutadas por estudiantes del nivel medio superior, se pueden mitigar problemas ambientales de la escuela y comunidad, así como desarrollar conocimientos, valores, habilidades y competencias en los jóvenes para conservar su ambiente (Espejel y Flores, 2012).

En cuba se ejecutó una investigación titulada: la protección del medio ambiente y la salud, un desafío social y ético actual, la cual busco exponer la implicación de los seres humanos en el deterioro ambiental, observando cómo el contexto está repercutiendo negativamente en la salud, además, se abordó la influencia positiva de la educación ambiental en la conservación del entorno, a partir de información disponible en anuarios y revisión de resultados de investigaciones (Rodríguez, Bustamante y Mirabal, 2011).

En Venezuela se realizó una propuesta de un programa de educación ambiental para la conservación del agua y recolección de residuos sólidos, aplicable a las comunidades, El programa constó de charlas que impartidas por los alumnos que cursaban el Servicio Comunitario en 
la Universidad de Oriente, hacia las comunidades abarcando diferentes niveles educativos (Carrato y Marval, 2007).

A nivel nacional en Cali, se realizó un estudio titulado: diseño de un proyecto de ahorro y uso eficiente del agua, como estrategia que sensibiliza en el cuidado del recurso hídrico, a los estudiantes de la Institución Educativa Juan Pablo II del Municipio de Palmira Valle, esté se presentó como una estrategia de intervención caracterizada tanto en su componente pedagógico como metodológico por ser participativa, flexible y práctica. Se fundamentó en la observación y estuvo orientada al aporte de herramientas conceptuales y prácticas que permitieran la participación de la comunidad educativa en el análisis de la realidad social y la búsqueda de alternativas de solución frente a los altos niveles de desperdicio y consumo inadecuado del agua en los niveles de básica primaria y secundaria (Granados, Holguín y Perdomo, 2015).

Finalmente, en Bogotá, se desarrolló un estudio de antecedentes sobre la contaminación hídrica en Colombia, el cual mostro a nivel general las principales alteraciones del recurso hídrico, realizó una descripción detallada de las principales formaciones geográficas en Colombia, como también presento la normatividad y jurisprudencia nacional frente a las políticas de protección ambiental (Segura, 2007).

\section{Educación ambiental para el mantenimiento de cuerpos de agua contaminados mediante la IEP}

Existen nuevas estrategias educativas para entender y mitigar, desde diversos puntos de vista, el deterioro ambiental actual. La educación ambiental (EA) es una herramienta para que las personas adquieran conciencia sobre la importancia de preservar su entorno, fomentando el cambio de conductas, valores y estilos de vida, así como ampliar sus conocimientos para impulsarlos a la acción mediante la prevención y mitigación de problemas existentes y futuros. La (EA) está orientada hacia la acción, esta debe involucrar a los estudiantes en el tratamiento de problemas reales y concretos, sin conformarse con la mera discusión de posibles soluciones. Se trata de prepararse para la acción ambiental, de adquirir capacidades generales, habilidades y rutinas concretas mediante estrategias de mejora del medio (Espejel y Flores, 2012).

Para ello:

Cifuentes, G (2013) concluye que la normatividad ambiental expedida por el Congreso de la República y reglamentada por el Gobierno Nacional ha de tener un carácter general que permita a las autoridades locales su desarrollo y adaptación acorde con las condiciones ambientales de cada municipio considerado separadamente, siempre que no contraríe la normatividad superior ni perturbe la denominada armonía regional (p. 361)

Es necesario recalcar que, esta es un proceso educativo planificado que busca suministrar instrucciones basadas en los más recientes datos científicos, al igual que en el sentimiento público prevaleciente diseñado para apoyar el desarrollo de actitudes, opiniones y creencias que apoyen a su vez la adopción sostenida de conductas que minimicen lo más que sea posible la degradación del ambiente original o las características geológicas de una región, la contaminación del agua, aire o suelo, y las amenazas a la supervivencia de otras especies de plantas y animales, de esta manera la educación ambiental busca propiciar la adquisición de conocimientos para la comprensión de la estructura del medio ambiente, suscitando comportamientos y actitudes que hagan compatibles la mejora de las condiciones de vida con el respeto y la conservación 
del medio desde un punto de vista de solidaridad global para los seres humanos (Carrato y Marval, 2007).

Así mismo, la (EA) pretende lograr un cambio de enfoque, desempeñando un papel esencial en la comprensión y análisis de los problemas socioeconómicos, despertando conciencia y fomentando la elaboración de comportamientos positivos de conducta con respecto a su relación con el medio ambiente, poniendo de manifiesto la continuidad permanente que vincula los actos del presente a las consecuencias del futuro (Carrato y Marval, 2007).

La (EA) está guiada bajo 4 niveles o componentes para su ejecución: iniciando por los fundamentos ecológicos; este nivel incluye la instrucción sobre ecología básica, seguido de concienciación conceptual; este consiste en mostrar cómo el conocimiento de la normatividad ambiental puede ayudar a guiar las conductas humanas, fomentando el cuidado del medio, en tercer lugar, la investigación y evaluación de problemas; este implica aprender a investigar y evaluar problemas ambientales, finalmente; la capacidad de acción; componente que enfatiza en dotar a la comunidad con habilidades necesarias para participar productivamente en la solución de problemas ambientales presentes y en la prevención de problemas ambientales futuros (Carrato y Marval, 2007).

En la actualidad se hacen evidentes los efectos de las actividades humanas sobre la calidad del agua, cuando no se dispone de mecanismos efectivos para el control y tratamiento del vertido de desechos, estos terminan siendo arrojados en algún cuerpo de agua superficial, en efecto las aguas superficiales son la parte de la hidrósfera terrestre que más deterioro presentan gracias a su capacidad de transportar cualquier cantidad de materiales sean líquidos o sólidos (Castillo y Rangel, 2012).
La realidad existente en torno al agua luce crítica, la misma está caracterizada por la manifestación de problemas como la contaminación y la sequía, los cuales están relacionados con algún tipo de intervención antrópica. De acuerdo con el informe de la secretaría del Convenio sobre la Diversidad Biológica (CDB) referente a la Perspectiva Mundial sobre la Diversidad Biológica (2010), son los ecosistemas de aguas superficiales, donde se ha sentido con mayor rigor los efectos de las acciones humanas de índole socioeconómica como la agricultura, el desarrollo industrial y las descargas residuales durante décadas (Castillo y Rangel, 2012).

La calidad del agua es el conjunto de características organolépticas, físicas, químicas y microbiológicas propias de este recurso, los cuerpos de agua están conectados entre sí desde la atmosfera hasta el mar a través del ciclo hidrológico, la calidad de los cuerpos del agua puede medirse en tres campos; hidrodinámica, fisicoquímica y bilógica. Para una caracterización completa de la calidad del agua es importante considerar el seguimiento de los campos mencionados (Padilla, 2006).

El agua, además de ser una sustancia imprescindible para la vida, por sus múltiples propiedades, es ampliamente utilizada en actividades diarias tales como; agricultura, industria, uso doméstico, entre otras, convirtiéndose en uno de los recursos más apreciados en el planeta. De ahí la importancia de conservar y mantener la calidad de las fuentes naturales, de manera que se garantice su sostenibilidad $\mathrm{y}$ aprovechamiento para las futuras generaciones (Ávila y Estupiñan, 2009)

La eutrofización es un proceso natural en los ecosistemas acuáticos, producido por el enriquecimiento del cuerpo de agua con nutrientes. Durante los últimos 200 años el hombre ha acelerado este proceso modificando tanto la calidad del agua, como la estructura de comunidades biológicas 
debido al aumento en la carga orgánica e inorgánica de los cuerpos de agua. La eutrofización reduce considerablemente los usos potenciales que tienen los recursos hídricos, puesto que induce a la mortalidad de especies animales, a la descomposición del agua y al crecimiento de microorganismos como bacterias, entre otros. Además, en muchas ocasiones los microorganismos se convierten en un riesgo para la salud humana, como es el caso de los agentes patógenos transmitidos por el agua, que constituyen un problema mundial (Ávila, y Estupiñan, 2009).

La contaminación se plantea a nivel general como cualquier alteración física, química o biológica que ocasiona efectos adversos sobre el ambiente y los seres vivos, la contaminación hídrica se lleva a cabo por vertimientos, derrames, desechos, depósitos directos o indirectos de toda clase de materiales y generalmente todo hecho susceptible de provocar un incremento en la degradación de las aguas, modificando sus características físicas, químicas o bacteriológicas. (Segura, 2007)

Existen diferentes fuentes de contaminación hídrica, como se mencionó anteriormente los vertimientos de aguas residuales o desagües sin ningún tratamiento contaminan los cuerpos de agua superficiales donde se encuentran residuos fecales que contienen agentes patógenos que transmiten enfermedades como; bacterias, virus, protozoos, helmintos y cianobacterias. Estos microorganismos pueden causar enfermedades con diferentes niveles de gravedad, desde una gastroenteritis simple hasta cuadros graves de diarrea, disentería, fiebre tifoidea o hepatitis, lo cual no solo genera la contaminación del cuerpo de agua sino también a las personas que utilicen este recurso para su consumo (Ávila, y Estupiñan, 2009).

En Colombia, el Ministerio de Salud y Protección Social desde la Subdirección de Salud Ambiental, presenta un Informe Na- cional de Calidad del Agua para consumo humano (INCA) donde su reporte realizado para el año 2015 presenta las enfermedades vehiculizadas por el agua (EVA), las cuales fueron clasificadas según su asociación directa o indirecta con el agua y su prioridad para la salud (MINSALUD, 2016)

Entre las EVA directamente relacionadas y con alta prioridad, se encuentran las enfermedades diarreicas agudas (EDA), hepatitis A, cólera, fiebre tifoidea/paratifoidea, Leptospirosis, criptosporidiosis, giardiasis. Las enfermedades indirectas consideradas con prioridad media fueron, enfermedades transmitidas por alimentos (ETA), malaria, dengue, fiebre amarilla, chikungunya, zika, Leishmaniosis enfermedad de Chagas, ascaridiasis, esquistosomiasis, filariasis, infecciones intestinales por nemátodos, amebiasis, e infecciones respiratorias agudas (IRA). Para el análisis se tuvo en cuenta la base de datos de notificación de la incidencia de las EVA reportada al Sistema Nacional de Vigilancia en Salud Pública - SIVIGILA del año 2015 (MINSALUD, 2016)

Identificar las enfermedades vehiculizadas por el agua en Colombia permite conocer en qué medida la falta de acceso a agua potable afecta la salud de la población. Un importante insumo para estudiar las EVA es conocer la incidencia de estas enfermedades en el país, sin embargo, actualmente se desconoce la carga de morbilidad relacionadas con las EVA debido a que existe un gran número de enfermedades que conforman este grupo, las cuales son vistas de forma independiente, es el caso de las hepatitis A, fiebre tifoidea y paratifoidea, cólera, y las EDA como; criptosporidiosis, giardiasis, leptospirosis entre otras, asimismo, existen dificultades para investigar los factores de riesgo ambientales asociados a las EVA, que es esencial para determinar si el origen de las enfermedades está relacionado con el agua. (MINSALUD, 2016) (tabla 1). 


\section{TABLA 1}

Tasa de incidencia de las enfermedades relacionadas con el agua en el Magdalena, 2015.

\begin{tabular}{cccccc}
\hline $\begin{array}{c}\text { Entidad } \\
\text { territorial }\end{array}$ & $\begin{array}{c}\text { Tasa de } \\
\text { incidencia } \\
\text { de dengue }\end{array}$ & $\begin{array}{c}\text { Tasa de } \\
\text { incidencia de } \\
\text { chikungunya }\end{array}$ & $\begin{array}{c}\text { Tasa de } \\
\text { incidencia de } \\
\text { fiebre amarilla }\end{array}$ & $\begin{array}{c}\text { Tasa de } \\
\text { leishmaniosis } \\
\text { cutánea }\end{array}$ & $\begin{array}{c}\text { Casos de } \\
\text { Zika }\end{array}$ \\
\hline Magdalena & 142,2 & 451,0 & 0,0 & 0,9 & 311 \\
\hline
\end{tabular}

Fuente: MINSALUD, 2016.

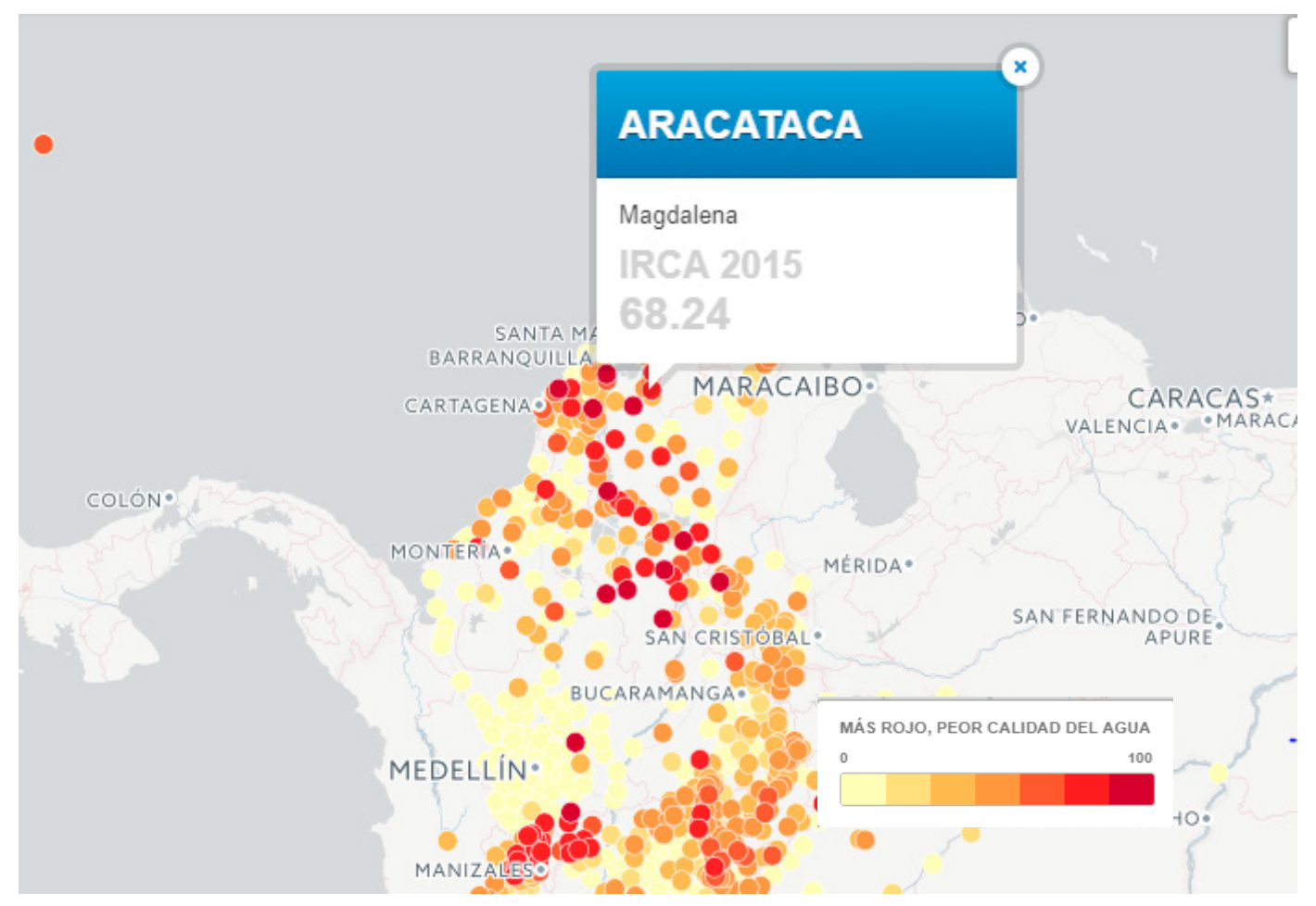

Figura 1. Índice de Riesgo de la Calidad del Agua para Consumo Humano. (Irca, 2015)

Por su parte el departamento del Magdalena cuenta con 30 municipios, de los cuales todos reportaron información sobre la calidad del agua en SIVICAP. La evaluación de la calidad del agua mediante el IRCA mostró que 10 municipios en nivel sin riesgo, 1 municipio en nivel de riesgo medio y 10 municipios en nivel de riesgo medio, no se observaron municipios clasificados en el nivel de riesgo bajo. Los municipios de Aracataca, Ariguani, Chibolo, Concordia, El Retén, Nueva Granada, Pijiño del Carmen, Pueblo viejo, Remolino, San Zenón, Santa Ana, Santa Bárbara de Pinto, Tenerife y Zona Bananera, mostraron IRCA en el nivel de riesgo alto, donde Sitionuevo y Zapayan en el nivel inviable sanitariamente (MINSALUD, 2016) (figura 1). 
Partiendo de las consideraciones anteriores, se observa que el municipio de Aracataca magdalena presenta un problema de contaminación en los cuerpos de agua superficiales, lo cual según los informes nacionales la puntúan con un riesgo alto en la calidad del agua, además, Según la Organización Mundial de la Salud (OMS), beber agua en condiciones que no son óptimas puede traer problemas de salud, evidenciados en las enfermedades vehiculizadas por el agua.

En la actualidad, existen propuestas metodológicas de enfoques basados en investigación, entendidos como la forma de materializar lo que se hace y como se implementa donde surgen infinidad de propuestas metodológicas que se basan en un enfoque o toman varios para hacer de ellos una propuesta metodológica; es el caso de las pedagogías basadas o fundadas en investigación, las cuales se desarrollan en diferentes contextos y asumen variados caminos en coherencia con los paradigmas y corrientes en los cuales se inscriben. Dentro de esta teoría basada en investigación se encuentra la Enseñanza por descubrimiento y el Programa Ondas, con su propuesta de la Investigación como Estrategia Pedagógica (IEP), como una perspectiva que se desarrolla en ese enfoque y toma elementos de la pedagogía critico-liberadora y del enfoque socio-cultural (Mejía y Manjarrés, 2010).

Los contenidos del proceso educativo se convierten en problemas, y a partir de preguntas se estructura el currículo, en donde los avances y desarrollos de los estudiantes se determinan por la ampliación de estructura previa que se manifiesta en lenguaje, raciocinios y conocimientos. Ese descubrimiento no es necesariamente autónomo, sino que se hace guiado por el profesor, quien se encarga de planificar los ejercicios y los procedimientos pare el fin buscado (Pozo, 2006).
En ese sentido, pensar la investigación desde las corrientes educativas criticas significa una lucha teórico-práctica por la manera como sus presupuestos sobre el conocimiento, la ciencia, su epistemología, la cultura, lo humano y los grupos sociales enmarcan una acción que durante cuatrocientos años ha sido señalada como objetiva, y que no solo ha construido una forma de ella, sino que también ha ayudado a generar formas de poder que en la sociedad han servido para el control y la gestación de desigualdades, y en estos tiempos, nuevas formas de acumulación y dominación (Ortega, 2009).

Durante el proceso de implementación de la IEP al aula de clase, se parte de la pregunta del sentido común de los niños, niñas y jóvenes para reelaborarla en la perspectiva de la educación popular, que reconoce la existencia de saberes comunes y elaborados así en la negociación con los conocimientos disciplinares, y de las maneras como se correlacionan en la negociación cultural (Mariño, 2010).

\section{Metodología}

Se realizó un estudio de tipo cualitativo, utilizando el modelo de investigación acción, desde un diseño descriptivo, exploratorio. La investigación cualitativa busca conocer e interpretar la realidad de los participantes a través de sus propias experiencias, entregando una información subjetiva del fenómeno de estudio. (Hernández, Fernández, y Baptista, 2010). Por su parte el modelo de investigación acción plantea una producción de conocimiento basado en la reflexión de los participantes, teniendo en cuenta la participación activa de maestros en el proceso de enseñanza y acompañamiento tecnológico, guiando al estudiante en su proceso de investigación. Generando nuevo saber y conocimiento sobre una realidad determinada en un proceso de aprendizaje colaborativo. 
Los estudios con un diseño descriptivo están encaminados a especificar las características de la población sujeto de estudio o los fenómenos que sean sometidos a análisis. Bajo un estudio de tipo exploratorio, debido a que no se han realizado estudios previos en la institución. (Hernández, Fernández, y Baptista, 2010). La población sujeto de estudio estuvo constituida por cincuenta (50) estudiantes, de los grados séptimo y octavo de básica secundaria, con edades comprendidas entre los once (11) y quince (15) años, para seleccionar la muestra se realizó un muestreo no probabilístico de tipo intencional seleccionando directa e intencionadamente los individuos de la población. Tomando como criterios de inclusión estudiantes del grupo de investigación ambiental.

Para la recogida de datos se utilizó la observación participante y el diario de campo, estas son técnicas de recolección cualitativas que implican que el docente tome un rol activo en el proceso de investigación, donde no solo debe estar como espectador del proceso de implementación, sino que también debe participar del mismo, registrando cada elemento observado con relación a la variable de estudio. En el diario de campo se registran y sistematizan los elementos obtenidos de la observación participante donde el contacto con las personas del contexto, modulan las reflexiones y conclusiones que se pueden extraer.

La metodología del proyecto de investigación se realizó a partir de los recorridos de las trayectorias de indagación, basados en la integración de la IEP al aula, articulado al plan de estudios, transversalizando así la educación ambiental a las diversas asignaturas, lo anterior con la finalidad de generar una trasformación social y educativa a través del aprendizaje en contexto, involucrando intereses, motivaciones $\mathrm{y}$ realidades de los estudiantes para generar conocimiento científico, donde se establecieron cinco (5) trayectos que especifican la ejecución y las metas trazadas para darle solución a la pregunta problema planteada. Los trayectos utilizados se presentan a continuación.

Trayecto (1): diseño de estrategias pedagógicas basadas en la investigación y las TIC transversales a las diferentes áreas de estudio, de acuerdo a las necesidades de la población para implementar la educación ambiental.

Trayecto (2): los docentes acompañaron al grupo de investigación conformado por estudiantes en el proceso de observación de las conductas que generaban contaminación en los diferentes afluentes del canal Tolima.

Trayecto (3): los estudiantes diseñaron estrategias para enseñar a la población a cuidar y mantener el recurso hídrico y que generaran conductas pro-ambientales.

Trayecto (4): análisis e interpretación de los resultados.

Trayecto (5): reflexión y apropiación social sobre los conocimientos generados en materia de estrategias pedagógicas para fomentar la educación ambiental.

\section{Resultados}

A continuación, se presentan los principales hallazgos del estudio, a partir de las observaciones realizadas, los docentes lideraron charlas de educación ambiental a los estudiantes de la institución educativa, a su vez los estudiantes buscaron información, indagaron sobre la problemática, realizaron salidas de campo al Canal para tomar fotografías que evidenciaran el problema y se dirigieron a la alcaldía a recolectar información sobre el mismo, ya que esta no aparecía en internet, seguidamente diseñaron carteles y los expusieron en la comunidad, buscando crear conciencia sobre el problema de contaminación hídrica presentada en el municipio, proponiendo estrategias de limpieza con los entes reguladores del municipio y la comunidad. 
A su vez, los docentes diseñaron unas actividades a realizar las cuales se detallan a continuación (tabla 2 )

TABLA 2

Actividades realizadas

\begin{tabular}{l}
\hline Actividades \\
\hline Charlas de educación ambiental \\
Aplicación de encuestas por parte de los \\
estudiantes a la comunidad \\
Salidas de campo \\
Diseño de cartillas educativas \\
Elaboración de un mural en la orilla del canal \\
Jornadas de limpieza con los entes reguladores \\
y la comunidad
\end{tabular}

Fuente: elaboración propia.

Según los registros llevados por los estudiantes en el diario de campo a partir de sus observaciones se encontró que los principales contaminantes del canal Tolima son residuos sólidos como; basura, plástico, material orgánico, heces fecales, detergentes metales y químicos producidos por empresas. Partiendo de lo anterior los estudiantes se reunieron para diseñar estrategias que permitieran el fomento de acciones para recuperar el canal Tolima, entre ellas plantearon las siguientes; jornadas de limpieza y recolección de desechos residuales, charlas de concientización a la comunidad, colocar publicidad en el municipio para crear sentido de pertinencia y realizar jornadas educativas frente a los riesgos de contaminación del agua.

\section{Conclusiones}

Se concluye que la implementación de la IEP al aula implica un proceso de integración curricular que posibilite el proceso enseñanza - aprendizaje, partiendo del hecho que las generaciones infantiles y juveniles son nativos digitales, es necesario impartir una formación en ciencia tecnología e innovación, visionando cambios y trans- formaciones en las dinámicas educativas, de esta manera el maestro a través de la reflexión de su práctica pedagógica puede apoyarse en las pedagogías basadas en investigación, para realizar comunidades de aprendizaje, con la finalidad de generar nuevo saber y conocimiento a través de un aprendizaje en contexto, donde el estudiante logre asociar la teoría a la práctica, propiciando un aprendizaje significativo.

Donde a través de las estrategias educativas basadas en la investigación se pueden generar mecanismos de recuperación de los cuerpos de agua contaminados en el municipio de Aracataca, formando estudiantes con conciencia ciudadana, que aporten a la preservación del medio ambiente, fortaleciendo competencias ciudadanas y mecanismos de participación en problemáticas ambientales propias de su contexto social.

Se hacen evidentes los efectos de las actividades humanas sobre la calidad del agua de esta vertiente, cuando no se dispone de mecanismos efectivos para el control y tratamiento del vertido de desechos, estos terminan siendo arrojados en algún cuerpo de agua superficial. El cuerpo de agua del canal Tolima se encuentra contaminado por conductas propias de la población del municipio, donde se espera que a partir de las estrategias diseñadas por el grupo de investigación de estudiantes con el apoyo de maestros sirvan para el cuidado y mantenimiento de este cuerpo de agua, mediante la creación de consciencia ambiental.

\section{Referencias}

Albis, A., Ortiz Toro, J., \& Martínez De la Rosa, J. (2017). Remoción de cromo hexavalente de soluciones acuosas usando cáscara de yuca (Manihot esculenta): Experimentos en columna. INGE CUC, 13(1), 42-52. https://doi. org/10.17981/ingecuc.13.1.2017.04 
Carrato, A. y Marval, R. (2007). Propuesta de un programa de educación ambiental para la conservación del agua y recolección de residuos sólidos, aplicable a las comunidades. Universidad del Oriente, Venezuela.

Domínguez, J., Marcos, C., Chao, Y., Delgado, G. y Rodríguez, D. (2012). Estudio de aguas continentales mediante teledetección. Editorial UNED.

Espejel, A. y Flores, A. (2012). Educación ambiental escolar y comunitaria en el nivel medio superior, Puebla-Tlaxcala, México. Revista mexicana de investigación educativa. Recuperado de http:// w w w. s c i elo.org. m x/s c i elo. $\mathrm{p} h \mathrm{p}$ ? $\mathrm{s}$ c $\mathrm{r}$ i p t $=\mathrm{s}$ c i arttext\&pid=S1405-666620120004 00008\&lng $=$ es\&tlng $=$ es.

Granados, L., Holguín, V. y Perdomo, M. (2015). Diseño de un proyecto de ahorro y uso eficiente del agua, como estrategia que sensibiliza en el cuidado del recurso hídrico, a los estudiantes de la Institución Educativa Juan Pablo II del Municipio de Palmira Valle. Santiago de Cali: Fundación Universitaria los Libertadores.

Guía del Instructor de Laboratorio, (2011) Contaminación del agua y reciclaje como una solución. Guatemala: Universidad de San Carlos de Guatemala.

Hernández, H. y Jiménez , A. (2015). Responsabilidad social empresarial, zona urbana del distrito de barranquilla: estudio etnográfico. Económicas CUC, 36(2), 9-18.

Hernández, R., Fernández, C. y Baptista, P. (2010). Metodología de la investigación. México, D.F.: Editorial Mc Graw Hill.

Irca. (2015). Indice de Riesgo de la Calidad del Agua para Consumo Humano. Recuperado de: http://www.eltiempo.com/ multimedia/especiales/calidad-del-aguaencolombia /16555 634/1/index.html.
Mariño, G. (2010). El diálogo en la educación de jóvenes y adultos. Dos propuestas pedagógicas para implementarlo. En, El taller dialógico I la recuperación de experiencias laborales. Bogotá, D.C.: OEI.

Mejía, M. y Manjarrés, M. (2010). La Investigación como Estrategia Pedagógica. Programa Ondas - Colciencias.

Mendoza, D., López, D. y Salas, E. (2016). Planificación estratégica de recursos humanos: efectiva forma de identificar necesidades de personal. Económicas CUC, 37(1), 61-79.

Morgado Gamero W.B., Ramírez M.C., Parody A., Viloria A., López M.H.A., Kamatkar S.J. (2018). Concentrations and Size Distributions of Fungal Bioaerosols in a Municipal Landfill. In: Tan Y., Shi Y., Tang Q. (eds) Data Mining and Big Data. DMBD. Lecture Notes in Computer Science, 10943. Springer, Cham

Navarro, R. y Garrido, S. (2006). "Construyendo el significado del cuidado ambiental: un estudio de caso en educación secundaria”, Reice. Revista electrónica iberoamericana sobre calidad eficacia y cambio en educación (España), 4(1). 52-70. Disponible en http://www.redalyc.uaemex.mx/ pdf/551/55140106.pdf

Ortega, P., Peñuela, D. y López, D. (2009). Sujetos y prácticas de la pedagogía crítica. Bogotá, D.C.: Ediciones El Búho.

Padilla, E. (2006). Derecho de aguas. Capitulo II aspectos técnicos $\mathrm{N}^{\circ} 4$. Calidad de los cuerpos de aguas. Bogotá, D.C.: Librería ediciones del Profesional.

Pereira, M. (2016). Hacia la construcción de un derecho energético ambiental como disciplina autónoma. Jurídicas CUC, 12(1), 177-204. http://dx.doi. org/10.17981/juridcuc.12.1.2016.10 
Pozo, J. y Gómez, M. (2006) Aprender y enseñar ciencia. Madrid: Ediciones Morata. 5ta. Edición.

República de Colombia. MINSALUD. (2016) Ministerio de Salud y Protección Social, Subdirección de Salud Ambiental. Informe Nacional de Calidad del Agua para Consumo Humano. Bogotá, D.C.: INCA.
Rodríguez, V., Bustamante, A., Leticia, M. y Mirabal, J. (2011). La protección del medio ambiente y la salud, un desafío social y ético actual. Revista Cubana de Salud Pública, 37(4), 510-518. Recuperado de http://scielo.sld.cu/scielo. php?script=sci_arttext\&pid=S0864$34662011000400015 \& \operatorname{lng}=$ es\&tlng=es.

Segura, L. (2007) Estudio de antecedentes sobre la contaminación hídrica en Colombia. Bogotá, D.C.: Escuela superior de administración pública ESAP. 